\title{
Continuous grid monitoring to optimize sedimentation management
}

\author{
Thomas Van Hoestenberghe, Roel Vanthillo
}

Fluves, Ghent, Belgium

Philipp Heidinger, Jürgen Dornstädter

GTC Kappelmeyer, Germany

Nik Dezillie, Nele Van Ransbeeck

VMM, Brussels, Belgium

\begin{abstract}
Fluves and GTC monitor since November 2015 continuously a sediment trap with dimensions $200 \times 20$ meters managed by the Flemish Environmental Agency (VMM) in Belgium. The continuous followup of sedimentation of the trap provides insights on temporal and spatial evolution of trapping efficiency. VMM will use the insights to optimize operational dredging decisions and for optimizing the design of future traps. The installed measuring system is based on distributed temperature sensing with a fiber optic cable of more than $2 \mathrm{~km}$. A digital terrain model (DTM) of the sediment trap is transmitted to the client on a hourly to daily basis. Results after winter floods from November 2015 till February 2016 show a significant spatial variation in sedimentation through the sedimentation trap. Also, zones with different temporal evolution of filling of the trap could be observed. The technique shows great potential for detailed spatial and temporal observation of sedimentation processes in large areas, as well as the ability to detect thin sedimentation layers.
\end{abstract}

\section{PROJECT GOAL}

VMM, responsible for unnavigable watercourses in Flanders, wants to have more insights in sediment dynamics in the sediment traps installed on their watercourses. The annual cost of dredging is high, and sediment traps installed in rivers or waterways can decrease dredging costs by concentrating sedimentation, such as on the Elbe estuary near Hamburg (HPA, 2013).

In Flanders many sediment traps are recently installed in upstream area of watersheds to trap sediment before contamination occurs more downstream (Ferket et al., 2014). Sediment traps are nowadays roughly monitored by bathymetric measurements. The trapping efficiency, which describes the fraction of total sediment entering the trap that remains in the trap, is in most cases unknown.

By monitoring the sedimentation continuously, it becomes clear when the trapping efficiency start to decrease. With this knowledge, decision can be taken when to dredge the trap. But more important, these insights will enable the river manager to enhance the design for future traps. Also, the measurement data can be very useful for erosion and sediment transport modeling.

\section{MATERIALS \& METHODS}

\subsection{Distributed temperature sensing}

Fiber-optic Distributed Temperature Sensing (DTS) has become a popular tool in environmental monitoring.

With DTS, fiber-optic cables are used as temperature sensors. Temperature can be measured at resolutions of $25 \mathrm{~cm}$ to $1 \mathrm{~m}$ along cables several kilometers in length, and the measurement interval can be under a minute. It has been used to provide both qualitative and quantitative information on many processes with a thermal signature (Solcerova et al., 2015). Two types of DTS measurements are used. In "Passive DTS", cables are used to monitor the natural temperature dynamics in the soil. Soil thermal properties can be calculated from the difference in amplitude and phase between temperature measurements at different depths. In "Active DTS", the cable is heated, and the fiber monitors temperature changes in the cable. The temperature response in the fiber can be directly related to the soil moisture, or equivalently the thermal properties of the surrounding soil. In addition to monitoring soil temperature and moisture, the thermal conductivity determined from either Passive or Active DTS can be combined with the temperature profile to estimate the soil heat flux (SteeleDunne et al., 2012).

Sebok et al. (2012) conducted measurements with a 750 meters fiber optic cable and DTS in the Holtum stream in Western Denmark to find spatial and 
temporal evolution of newly deposited sediments. They could identify the existence of scouring, migration, and re-deposition events.

For this project, a fiber optic cable of more than 2 $\mathrm{km}$ was installed in a grid pattern in a sediment trap. Spatial resolution of the measurement grid is almost every $\mathrm{m}^{2}$. From the temperature measurements, the sediment height on the cable could be quantified.

\subsection{Site characteristics}

In figure 1, the location of the sediment trap is shown. The trap is situated in the southern part of Flanders, near Geraardsbergen.

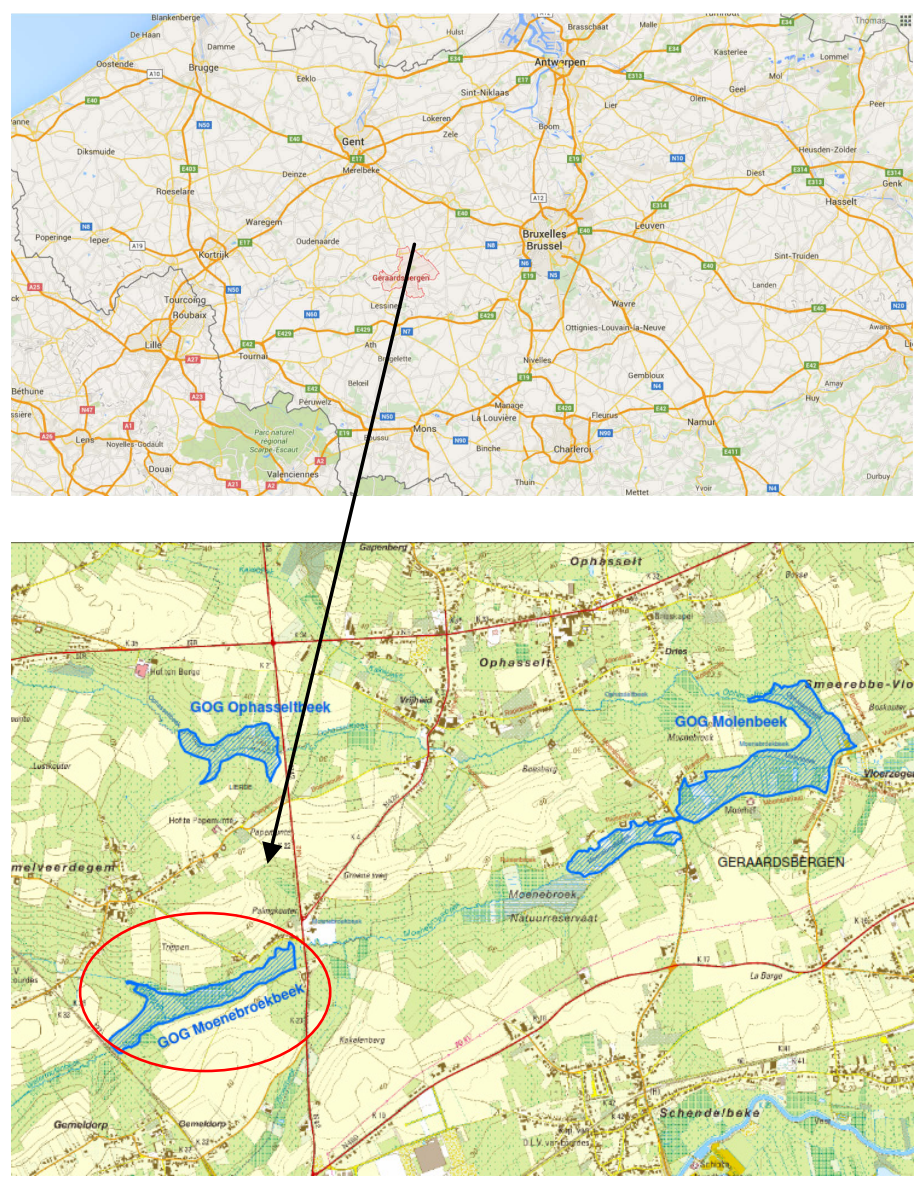

Figure 1. Position of the sediment trap in upstream area of Molenbeek Hasselt (Flanders, Belgium)

The trap is installed in a flood control area (FCA) on the river 'Moenebroekbeek', an upstream branch of the Dender river, a tributary of the Scheldt river. Average river discharge is $500 \mathrm{l} / \mathrm{s}$. The sediment type that enters the FCA is fine loam, typically with medium grain size of $10-20 \mu \mathrm{m}$. The sediment transported by the river to the FCA and deposited in the trap has mainly it's origin in soil erosion processes from the adjacent agricultural land. The estimated annual sediment transport towards the trap is 1500 ton. With an expected trapping efficiency of $25 \%$, the trap would need to be dredged every 10 years (VMM, 2010).

The sediment trap is an enlargement and deepening in-line with the river. The sediment trap is in the center of a larger FCA. The width of the trap is on average $20 \mathrm{~m}$ and the total length is $200 \mathrm{~m}$. The bottom of the trap is at level $23 \mathrm{~m}$ TAW (Tweede Algemene Waterpassing = local sea reference level), somewhat lower than the incoming river. A gate at the downstream part of the FCA controls the filling of the FCA. When water level in the river downstream the gate rises to a certain level, the downstream gate reduces the flow through the gate and the FCA fills.

During three flood events in the period November 2015 till February 2016, the FCA was filled. Filling started in 2015 at a downstream water level of 24.25 mTAW and in 2016 at an downstream water level of $25.00 \mathrm{mTAW}$. During the flood event of 20/11/2015, the FCA was filled for $15 \mathrm{~h}$. During the flood events from 15 till 16 January 2016 and 9 till 11 February 2016 , the FCA was filled for $16 \mathrm{~h}$ respectively $24 \mathrm{~h}$, but filling started only at $25 \mathrm{mTAW}$. There were several minor flood events where the water level upstream the gate did not reach 25 mTAW. The flood event from 9 till 11 February 2016 was the event with most flood volume and longest retention period of flood water in the FCA.

\subsection{Measuring method}

The sediment height is measured throughout the pool by combining direct and indirect measurements. At 20 locations, evenly distributed in the pool, the soil/water interface is measured directly by winding the fiber optic cable around vertical poles (Figure 2).

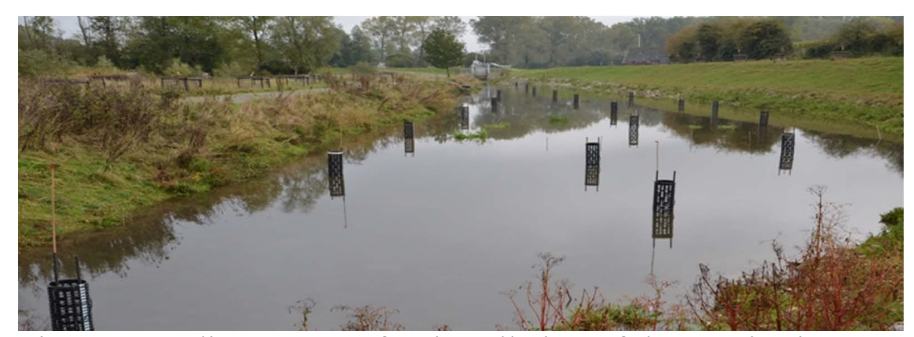

Figure 2. Sediment trap after installation of the monitoring system with 20 vertical poles throughout the trap

In order to determine the difference in thermal parameters of the water and sediment, the "Active DTS" - method is used. An electrical current is sent through an electrical conductor, installed together with the fibre optic cable. This cable system can be heated up considerably. The temperature increase of the surroundings of the cable is dependent on the heat capacity and heat conductivity of the water or sediment. Water, especially when flowing, cause a reduced heat up of the cable compared to sediment (GTC, 2001).

The DTS unit measures the thermal response of the heating for all measurement points along the cable, one value every $25 \mathrm{~cm}$. The DTS installed for this application is from manufacturer APSensing (Figure 3). Fluves cooperated with GTC Kappel- 
meyer $\mathrm{GmbH}$ for the installation and configuration of the system.

When the cable is surrounded by water, the thermal response will be high. When the cable is buried in sediments, the response will be low. Because the installation layout is known, the results can be transformed from fiber meter distance to height of the poles. Then the threshold from low to high thermal responses marks the upper boundary of sedimentation.

Sediment height can be measured with an accuracy of $1 \mathrm{~cm}$ at these 20 poles.

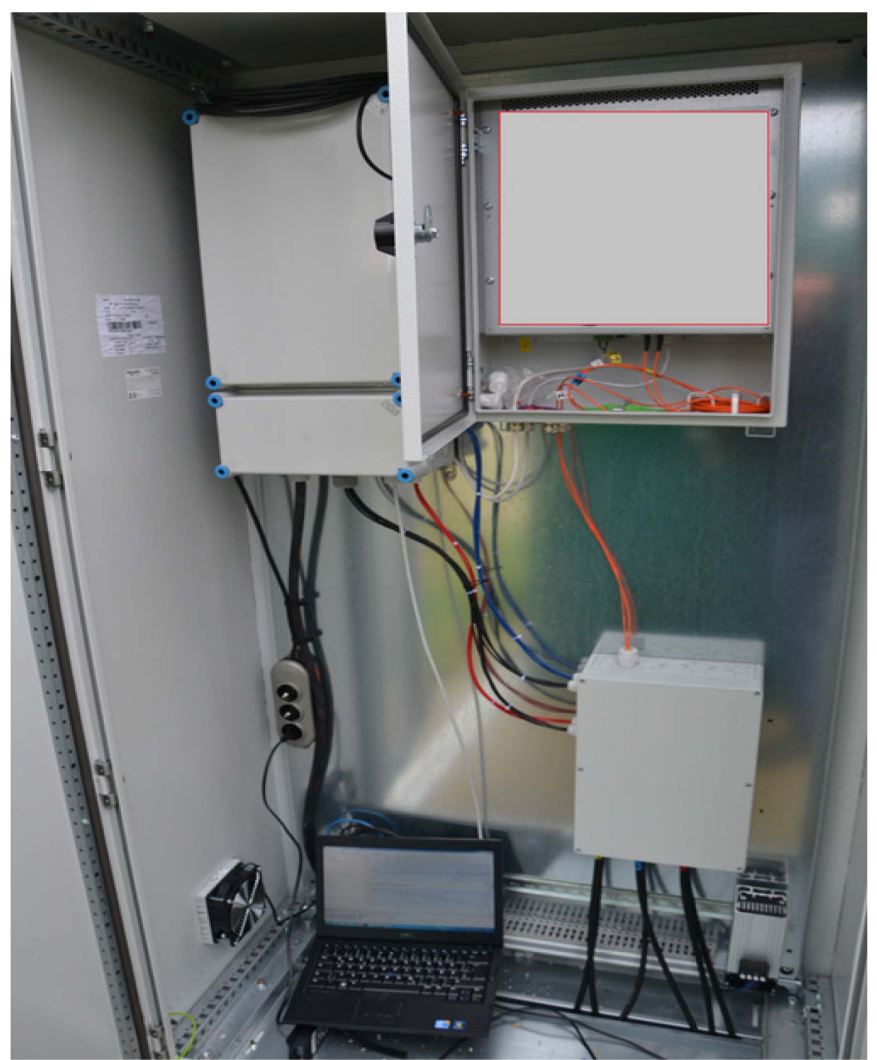

Figure 3. DTS instrument from APSensing and auxiliary equipment for the heating cycles. The system is remotely controlled.

In between the poles, the cable is installed horizontally on top of the base level of the sediment trap. To be able to measure the sediment accumulation indirectely in between the poles, the hybrid fiber optic cable is configured in a pattern as described in Figure 4. In the upstream part, a detailed grid of $5 \mathrm{~m}^{2}$ was installed in a separate loop. As can be seen from Figure 4, the cable was largely uncovered immediately after installation. Some parts were already covered with a thin layer of sediment, partly due to manipulation of the sediment layer during installation.

Several GPS measurements of the sediment height were performed at the poles to validate the sedimentation by the fibre optic measurement system. The GPS used for the validation measurements was a Leia GS12. The accuracy of the fiber optic measurements was within the error margin of +-2 $\mathrm{cm}$ of the GPS measurements.
By using a long heat pulse (multiple hours), the thermal response can be analysed in areas at further distance from the cable. The heating curve is influenced by the thickness of the sediment layer and the thermal diffusivity. The thermal diffusivity is an unknown parameter, dependent amongst others on soil moisture content and density of the sediment. But at the poles, where the thickness of the sediment is known, the thermal diffusivity can be calculated. So the poles measurement serve as a (continuous) calibration for the measurements in between the poles.

The accuracy of these indirect sediment height measurements will be assessed during 2016 with several detailed bathymetrical campaigns.

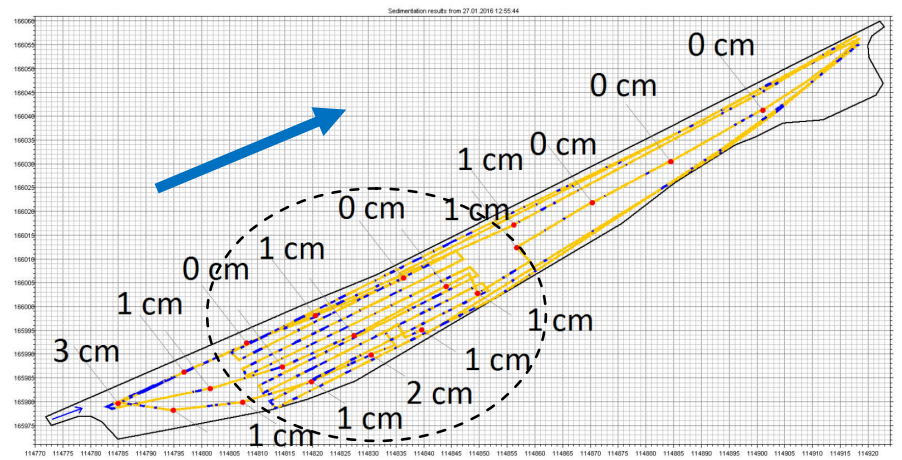

Figure 4. Sediment trap with vertical poles (red) and complete horizontal layout of fiber cable throughout the trap (above) 1 week after installation $\left(14^{\text {th }}\right.$ of October 2015$)$. At each pole, the sedimentation height is given in $\mathrm{cm}$. In between the poles, blue color of cable indicates no sediment on top of the cable and yellow indicates sediment on top of the cable. Within the dotted circle the separate loop with detailed grid is situated. The blue arrow shows the flow direction.

The cable was installed during the first week of October 2015. The system became fully operational with hourly to daily delivery of a digital terrain model by the end of October 2015.

\section{RESULTS}

\subsection{Spatial variation}

In Figure 5, sedimentation heights are shown for the direct measurements after several flooding events in the period November 2015 till beginning of February 2016. During three flood events, the FCA was filled with a thin layer of sediment. The flood event from 9 till 11 February 2016 was the event with most flood volume and longest retention period of flood water in the FCA.

The sedimentation height between beginning of February 2016 and November 2015 is on average 5 $\mathrm{cm}$. This is less than what was expected before the start of the measurements. At the most upstream area, significantly less sedimentation is measured (less than $3 \mathrm{~cm}$ ). In contrast, in the middle of the trap, a zone with distinctly more sedimentation can be observed, up to $9 \mathrm{~cm}$. At the sides of this sedimentation zone, again less sedimentation occurred $(<3 \mathrm{~cm})$. In 
the most downstream part of the pond, a uniform sedimentation of 4 to $5 \mathrm{~cm}$ is observed.

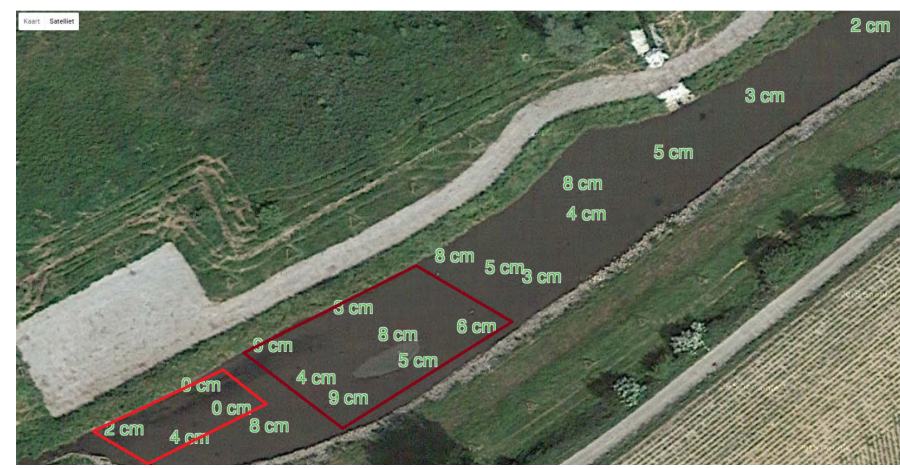

Figure 5. Sedimentation height in centimeters between November 2015 and begin February 2016 at the 20 direct measurement locations. Red and brown zones indicate the locations with respectively less and more sedimentation than the average sedimentation rate (i.e. $5 \mathrm{~cm}$ ).

A reason for these spatial variation could not yet be identified. There is no correlation between initial base level of a specific location in the pond and the corresponding sedimentation rate. Local eddies and local vegetal obstruction are the most plausible explanation of these spatial variation in sedimentation.

For the indirect measurements between the poles, a detailed pattern of the sedimentation height for 26th of January 2016 and 20th of February 2016 is shown for the detailed grid (separate loop) in Figure 6 . Floods between the end of January and mid February increased the thickness of the sedimentation layer in the trap, but the thickness varies considerably in the trap. In Figure 6, blue indicates no sedimentation, red indicates an average sedimentation $(4-5 \mathrm{~cm})$ and green is at least $7 \mathrm{~cm}$ sedimentation since October 2015. The patterns shown in Figure 5 are confirmed but more in detail: little sedimentation in the upstream part and more sedimentation in the middle of the trap.

Since validation of the indirect measurements by detailed bathymetrical mapping will only take place later in 2016, assessement of the accuracy of the indirect measurements was not possible. The black circle in Figure 6 indicates a zone of 15 meters where the sediment $(5 \mathrm{~cm}$ thick) was removed from the cable on 19th February 2016. This zone of 15 meters without sediment is clearly shown in Figure 6 (bottom), which indicates that the indirect measurements are at least capable of monitoring the difference between no sediment and a sediment layer of 5 cm thick.
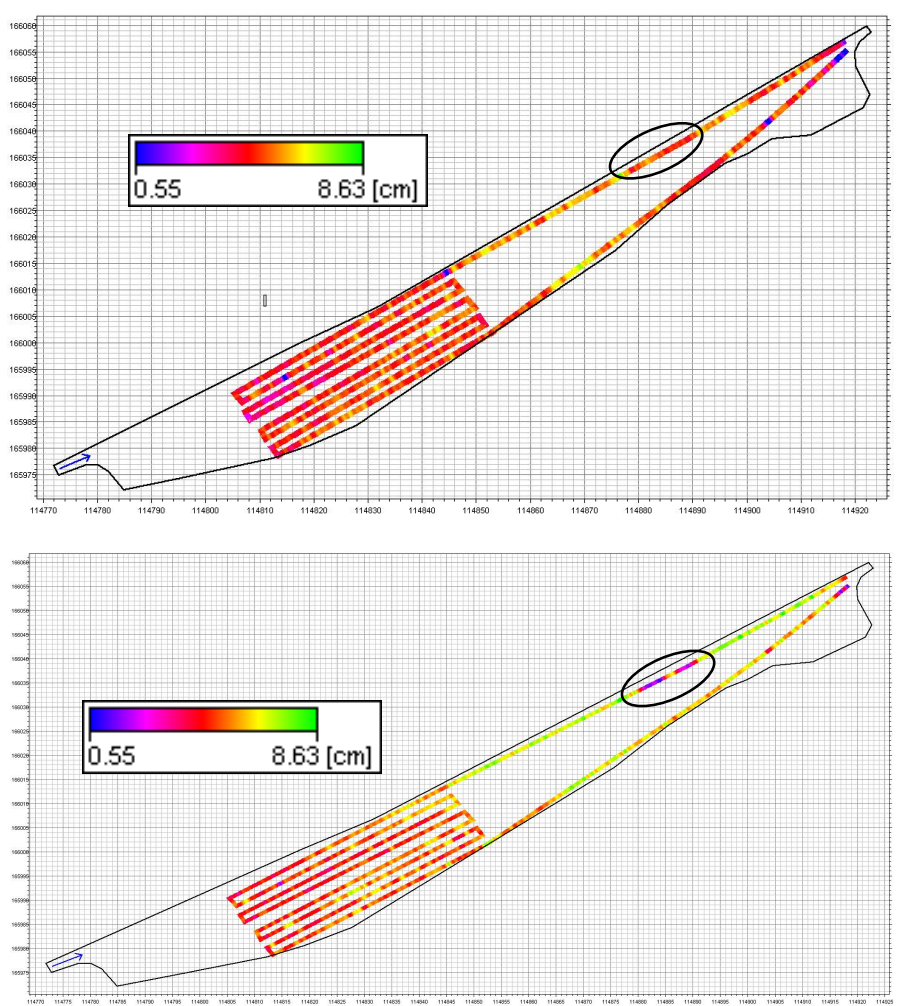

Figure 6 . Detailed pattern of sedimentation height on $26^{\text {th }}$ of January 2016 (Above) and 20 ${ }^{\text {th }}$ of February 2016 (Below). Blue is no sedimentation, red is average sedimentation $(4-5 \mathrm{~cm})$ and green is at least $7 \mathrm{~cm}$ sediment since October 2015. The black circle indicates a zone of 15 meters where the sediment was removed from the cable the $19^{\text {th }}$ of February 2016.

\subsection{Temporal variation}

Because sedimentation can be measured with an accuracy of $1 \mathrm{~cm}$ sediment height, sedimentation, erosion and redeposition can be monitored with great detail. In Figure 7, the evolution of sedimentation for the 4 vertical poles with more than $7 \mathrm{~cm}$ sedimentation between November 2015 and February 2016 is shown. There is a correlation between sedimentation rate with the water height, but the height and volume of flooding of the FCA is not the only explaining factor. The highest increase in sedimentation rate can be observed for the modest flood event begin January 2016. But at this event, the FCA was not even filled since filling starts at a water level of 25 mTAW. One would expect much higher sedimentation rates for the higher flood events of mid January and begin February 2016, when the FCA was filled and current velocity in the FCA slowed down.

Other observations are that at some locations there is some erosion directly after a flood event (decrease of sedimentation level), but this erosion is very limited. Once the sediment is deposited, it remains mostly stable. This also indicates that there are no significant consolidation processes, i.e. decrease of volume while mass conservation, once the sediment deposited in the trap. 


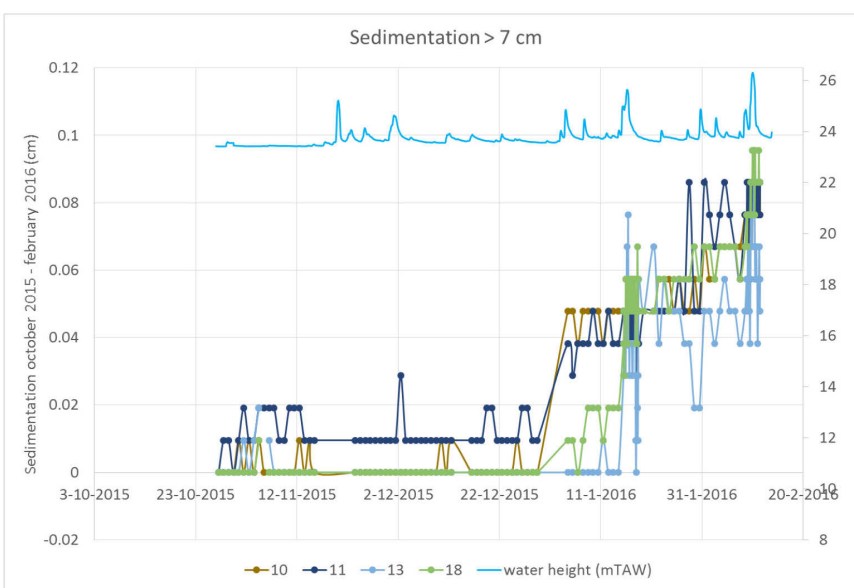

Figure 7. Time series of evolution of sedimentation for 4 poles with more than $7 \mathrm{~cm}$ sedimentation between November 2015 and February 2016. The blue curve is the water height (right Yaxis). The numbers $10,11,13$ and 18 refer to the location of the vertical poles, as shown in Figure 3.

In Figure 8, the evolution of sedimentation for some poles between the flood event between 7 and 9 February 2016 is given. For this event, we see a slow and modest sedimentation while the FCA is flooded. For most locations, the maximum sedimentation (only 2 to $3 \mathrm{~cm}$ ) decreases a little $(1 \mathrm{~cm})$ when the FCA empties.

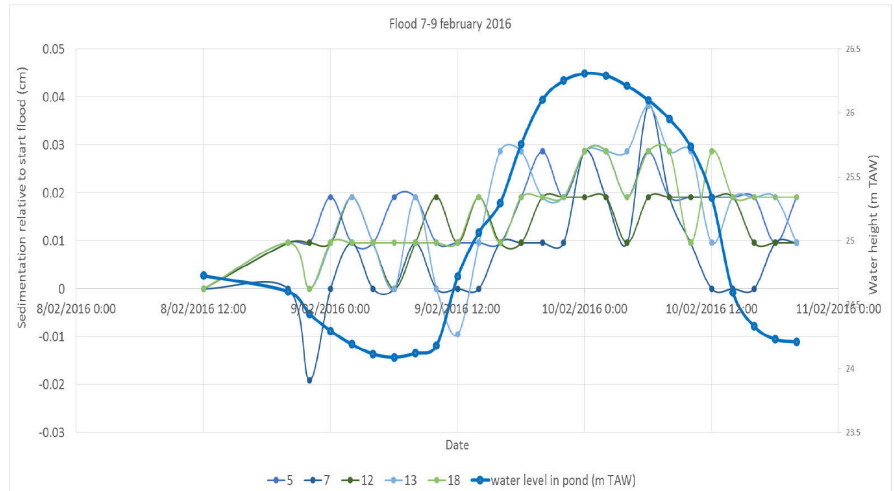

Figure 8. Time series of sedimentation evolution for some poles between the flood event between 7 and 9 February 2016. The blue curve is the water height (right $\mathrm{Y}$-axis). The numbers $5,7,12,13$ and 18 refer to the location of the poles, as shown in Figure 3.

\section{CONCLUSIONS}

With the recent developments in fiber optic measurement techniques, sediment matter dynamics can be monitored in a very detailed way both spatially and temporally. A continuous grid of a riverbed or lake can continuously be measured. The measurement system is not present in the water column, but is a cable installed beneath the sedimentation layer.

Both spatial and temporal variation of sedimentation in the sediment trap and erosion could be monitored in detail. Sedimentation rates after several flooding events in the period November 2015 till beginning of February 2016 are limited to less than 10 $\mathrm{cm}$. There is only a weak correlation between sedi- mentation rate and flood volume. Once sediment is deposited, only limited erosion or consolidation could be obeserved.

The indirect measurements (= between the poles) show a very detailed pattern of the sedimentation evolution. These indirect measurements are at least capable of monitoring the difference between no sediment and a sediment layer thickness of $5 \mathrm{~cm}$.

\section{REFERENCES}

Dornstädter, J., 2001. Description of fibre optic temperature sensing method. Memo GTC Kappelmeyer GmbH.

Ferket, B., Van De Broek, M., Van Hoestenberghe, T., Degerickx, J., De Sutter, R., Govers, G., Dezillie, N. \& Deproost, P., 2014. Erosion modelling towards, and sediment transport modelling in unnavigable watercourses in Flanders, Belgium. Sediment Dynamics from the Summit to the Sea (Proceedings of symposium New Orleans, Louisiana, USA, 11-14 December 2014). IAHS Publ. 367, 2014.

HPA, 2013. Pilot Project: 'Evaluation of the sediment trap near Wedel'. Measure analysis in the framework of the In-terreg IVB project TIDE. Measure 5. Hamburg Port Author-ity (HPA), Hamburg, Germany.

Sebok, E.; Duque, C.; Engesgaard, P.; Boegh, E. 2012. Distributed Temperature Sensing as a method to identify groundwater discharge zones and in-stream sedimentation processes in soft-bedded streams. Geophysical Research Abstracts

Vol. 14, EGU2012-2955, 2012.

Solcerova, Anna; van Emmerik, Tim; Hilgersom, Koen; van de Giesen, Nick. 2015. Practical considerations for coilwrapped Distributed Temperature Sensing setups. Geophysical Research Abstracts. Vol. 17, EGU2015-5506, 2015.

Steele-Dunne, S. C.; van de Giesen, N.; Jansen, J. H. A. M.; Hatch, C.; Selker, J.; Tyler, S.; Ochsner, T.; Cosh, M. H. 2012. Distributed Temperature Sensing as a tool for monitoring heat transfer processes in the shallow subsurface. Geophysical Research Abstracts. Vol. 14, EGU2012-6375, 2012.

VMM, 2010, Infokrant Wave Zandbergen. 